\title{
Health education guide book for swimming school learners
}

\section{Introduction and research problem:}

Health education is an effective means of improving the quality of society's health. Health education is both scientifically and operationally based because it has an important role to raise public health by acquiring information that fits his level of thinking to be able to understand the health conditions that are useful for him and get him to cooperate with all that's going on (1:19).

Clowely indicates (2009) that health education for swimmers starts at the beginning of swimming and in sync with learning the skills because attitudes and habits develop in the early years of learning to swim and have a powerful effect on solving later health problems or not showing up a tall.(7:116)

Dredd Majid confirmed that one of the damage caused by the pool was skin disease, swimming pool can be the source of toes dermatitis and hair can also be dehydrated and precipitated.(9:33)

The national specialized councils considered it necessary to promote health awareness among children and to reject bad health and social custom to help kids to turn on information to actual practices. So it is important to train a teacher in the basis of health knowledge to make him a healthy educator for the child (2:87).

According to the researcher healthy culture plays a major role in shaping healthy behaviors and trends, because healthy behaviors and trends, because healthy culture dominates our attitudes and healthy obvious differences in society.

The research problem shows that there researcher's job as a swimming teacher at faculty of physical education at Assiut University and supervised swimming academies during the summer, she noticed that many children are at risk of catching skin diseases and colds as result of unhygienic habits such as getting used to personal hygiene and un personal objects and special 
injures to eye and ear infections in swimming besides the injures that could result from not obeying a teacher's instructions. The researcher attributes this to the child's lack of healthy habits of swimming.

In the light of the foregoing and the recommendations of previous studies, for example Nisreen Abd-Elmajid(15) (2011) and (Miller \& Almon)(12) study (2009), it is essential to focus on health education for sports practitioners while learning, and as researcher, to develop a health education guide for swimming school learners. Health care and education saves the state its efforts and money in providing health care and treatment services, also an environment of health education and care engenders healthy and positive behaviors .

\section{The importance of research and the need for it:}

1. Familiarizing swimming teachers with the health habits, skills, knowledge and experience that learners in swimming schools need to acquire.

2. A swimming teacher may be able to use certain successful able targeted methods to inculcate proper hygiene before and after swimming.

\section{The purpose of the search:}

The aim of the search is develop a health education guide for swimming school learners by getting to know.

1. Aims of the educational guide for swimming school learners.

2. Content of the health education guidebook for swimming school learners.

3. Implementation of health educational guidebook for swimming school learner?

4. Evaluation methods for the health educational guidebook for swimming school learners. 


\section{Search questions:}

1. What are the objectives of the health educational guidebook for swimming school learners?

2. What is the content of the health educational guidebook for swimming school learners?

3. What are the implementation methods of the health educational guidebook for swimming school learners?

4. What are the evaluation methods for the health educational guidebook for swimming school learners?

\section{Search terminology:}

\section{Health culture:}

Is a process of translating known health facts into healthy behavioral patterns at the individual and community level, to change erratic attitudes and behavioral habits, so does helping one to acquire experience and practice proper hygiene.(1:14)

\section{The guidebook (manual):}

Is a book of experiences, knowledge and skills in which workers demonstrate the goals to be achieved, the methods to implement the goals, and the methods to develop their work.(7:31)

\section{Previous studies:}

Nisreen Nadi Abdul Jaid study (2001)(15) is entitled a guidebook on health education for primary education teachers, the aim of the study was to build a guide to the health education of primary school sports teachers by identifying the professional work requirements of primary school teachers in order to achieve the objectives of school health education. The researcher used the descriptive curriculum and her sample was (10) teaching staff and (230) sports teachers, and the most important result was the construction of guidebook for sports teachers to primary health education 


\section{Research procedures:}

The used curriculum: the researcher used the survey -based descriptive approach because it is suitable for the nature and conditions of the research.

\section{Research community:}

1. Faculty members faculties of physical education specialists in the field of water sports.

2. Faculty members faculties of physical education specialists in the field of sports health sciences.

3. Teaching staff working in schools in swimming and sport health sciences, and technical directors and swimming teachers working in swimming schools .

\section{Research sample:}

1. A sample was selected randomly, (60) of technical and swimming teachers from swimming schools in the clubs and special entities in assuit governorate.

\section{Data collection tools:}

The researcher analyzed the_content_of scientific references and studies relevant to the research (4),(9),(8),(16),(10),(13), (11),(15) and designedfour forms as follows:

- Questionnaire to target the content of healthy educational guidebook for swimming school learners.

- Questionnaire to determine the aims of healthy educational guidebook for swimming school learners.

- Questionnaire to determine the implementation methods of healthy educational guidebook for swimming school learners.

- Questionnaire to determine the evaluation methods of healthy educational guidebook for swimming school learners. 
The purpose of the form and the statistical were determined to ensure the authenticity and consistency of the respective forms within 15 days for the authenticity of the form and the preparation of the proposed guideline, this questionnaire was applied to (60) of teaching staff in swimming schools and sports health sciences from(5/1/2017) to $(25 / 4 / 2017)$.

Statistic processors: (percentage, arithmetical means standard deviation).

\section{Presentation and interpretation of result:}

Presentation and interpretation of results of the first question: what are the goals of the healthy educational guidebook for swimming school learners?

\section{$\underline{\text { Table(1) }}$}

\section{Estimated degree and percentage of sample responses to the goals}

\section{$(\mathrm{N}=60)$}

\begin{tabular}{|c|c|c|c|c|c|c|}
\hline No & The goals & agree & To same extend & $\begin{array}{l}\text { Don't } \\
\text { agree }\end{array}$ & $\begin{array}{l}\text { Estimated } \\
\text { degree }\end{array}$ & Percentage \\
\hline 1 & $\begin{array}{l}\text { The definition of health concepts } \\
\text { liked to health culture for } \\
\text { swimming learners. }\end{array}$ & 54 & 4 & 2 & 284 & $94.66 \%$ \\
\hline 2 & $\begin{array}{c}\text { Spread health awareness among } \\
\text { swimming learners. }\end{array}$ & 56 & 4 & ------- & 292 & 97.33\% \\
\hline 3 & $\begin{array}{l}\text { Working to develop and } \\
\text { strengthen health trends for } \\
\text { swimming learners. }\end{array}$ & 48 & 8 & 4 & 268 & $89.33 \%$ \\
\hline 4 & $\begin{array}{l}\text { To workout the proper rules and } \\
\text { habits of swimming in perfect } \\
\text { conditions. }\end{array}$ & 52 & 5 & 3 & 278 & $92.66 \%$ \\
\hline 5 & $\begin{array}{l}\text { The guide contains sufficient } \\
\text { information on disease linked to } \\
\text { swimming and how to prevent } \\
\text { them. }\end{array}$ & 50 & 6 & 4 & 272 & $90.66 \%$ \\
\hline 6 & $\begin{array}{l}\text { For the guide to change behaviors } \\
\text { and habits of swimming learners } \\
\text { to improve their health level }\end{array}$ & 54 & 5 & 1 & 286 & $95.33 \%$ \\
\hline
\end{tabular}


From the previous table :(1): it appears that the percentage of sample response from the research in the goals from ranged from (89.33\%:97.33\%).

The (2) sentence has the highest response but the (3) sentence has the lowest response.

The result of table (1) refer to the agreement of the dominant experts on all the goals because of its importance it was necessary for the proposed health education manual which indicates that they are suitable for what they are set up for it also points to the relevance and appropriateness of these statements by the researcher.

This was confirmed by Mona Mohamed Ali (2016) who stated that the concept of health education is essentially about counseling and communicating health with individuals in order to induce motivation and equip them with knowledge and skills needed to adopt healthy, good behavior, thus raising the standard of health or disease prevention.(14:79).

According to Samia Mansour Nasser study(2016), habit is a behavior that is acquired through education, and human habits are not inherited and health is the result of factors such as health customs is the process of guiding society to protect itself (16:41).

From the foregoing, it become clear to the researcher that the primary goal of health education is to be an educational process that involves improving healthy behavior a combination of learning experiences that are planned for health- enhanced behaviors for swimming learners.

Table (1) shows the multiplicity of health education manual in swimming .

The researcher concludes from previous result that the most important of these goals, which fall within the health experience of swimming school learners, is that learners must have several concepts which are :

The learners know the importance of personal hygiene both before and after swimming in the pool.

- To know personal items (towel, soap, comb.....) 
- To understand the necessity of not using other people's tools to avoid infection and certain skin diseases.

- To understand how to avoid eye and ear infections white swimming.

- To understand how to avoid cold whole swimming.

- Learning that swimming prevents some chronic asthma.

- To avoid injures that might occur in the pool by avoiding running around the pool and respecting swimming instructors.

Presentation and interpretation of results of second question:

What is the content of the health educational guidebook for swimming school learners?

\section{Table (2)}

\section{Estimated degree and percentage for sample responses in quide content} $(\mathrm{N}=60)$

\begin{tabular}{|c|c|c|c|c|c|c|}
\hline No & Content & Agree & $\begin{array}{l}\text { To some } \\
\text { extend }\end{array}$ & Don't agree & $\begin{array}{l}\text { Estimated } \\
\text { degree }\end{array}$ & $\begin{array}{l}\text { percenta } \\
\text { ge }\end{array}$ \\
\hline \multicolumn{7}{|c|}{ First:(axis one) health culture for swimming learner: } \\
\hline 1 & $\begin{array}{l}\text { ecncourage swimming learner to protect } \\
\text { themselves from epidemic and diseases }\end{array}$ & 54 & 6 & ------- & 288 & $96 \%$ \\
\hline 2 & $\begin{array}{l}\text { Providing health information and knowledge } \\
\text { for swimming }\end{array}$ & 49 & 6 & 5 & 268 & $89.33 \%$ \\
\hline 3 & $\begin{array}{l}\text { Following public and personal hygiene of } \\
\text { swimming learners }\end{array}$ & 48 & 7 & 5 & 266 & $88.66 \%$ \\
\hline 4 & $\begin{array}{l}\text { Common diseases caused by swimming } \\
\text { pools and how to prevent and treat. }\end{array}$ & 49 & 6 & 5 & 268 & $89.33 \%$ \\
\hline 5 & $\begin{array}{l}\text { Providing information and health facts } \\
\text { related to swimming pool }\end{array}$ & 57 & 3 & ----- & 294 & $98 \%$ \\
\hline \multicolumn{7}{|c|}{ Second(Axis two) health care for swimming learner: } \\
\hline 6 & $\begin{array}{l}\text { Combating swimming pool infectious } \\
\text { diseases }\end{array}$ & 55 & 5 & ----- & 290 & $96.66 \%$ \\
\hline 7 & $\begin{array}{l}\text { Emergency and first aid services for } \\
\text { swimming learners }\end{array}$ & 53 & 6 & 1 & 284 & $94.66 \%$ \\
\hline 8 & Providing essential drugs & 50 & 6 & 4 & 272 & $90.66 \%$ \\
\hline \multicolumn{7}{|c|}{ third(axis three) health services for swimming: } \\
\hline 9 & Healthy environment for swimming pools. & 51 & 7 & 2 & 278 & $92.66 \%$ \\
\hline 10 & $\begin{array}{l}\text { Periodic notes for } \\
\text { swimming learners }\end{array}$ & 47 & 7 & 6 & 262 & $87.33 \%$ \\
\hline 11 & Providing first aids for swimming learners & 52 & 6 & 2 & 280 & $93.33 \%$ \\
\hline
\end{tabular}


From the previous table(2): it appears that the percentage of sample responses of the research in the requirements from ranged from (84.66\%:96.66\%). The sentence no (4) has the highest response but the sentence no. (7) Has the lowest response.

The result table (2) refer to the agreement of the dominant experts on all sentences of the guidebook content because of its importance for presentation of all health information which is specific to the age stage and indicated that they are suitable for what they are setup for and appropriateness of these statements by the researcher.

These results are consistent with world health organization recommendations for 2018 that health education programs should cover multiple themes:

- Personal hygiene.

- Fighting common diseases.

- Proper health habits.

- A healthy life system like avoiding sleeplessness, stress and regulating hours of sleep and rest.

- Fighting against harmful habits: smoking -education.

- First aids.

- Common diseases in society and how to prevent and treat. (18) Environmental and personal health, as well as guide individual to healthy behavior and healthy habits, also identification of common injures at different age stages as well as infectious diseases and presentation methods .the researcher sees that it is important to be a complementarity between the fields of health education and that all of them are intertwined and tightly knit, so that the healthy personality of a swimmer and healthy behavior are built on each other.

Dourid Majid Hamdany(2016) points out that swimming pools are a fun place for swimming and leisure, but they are also a place for disease if care is not taken to provide safety and security to swimmers. 


\section{The most important factors are:}

- Water purification to ensure that it is used as long as possible.

- The competent examination of the pool parts to ensure its safety.

- Regulations, rules and guidelines on how to use pool tools.(8:223).

In this regard, he says that swimming education must include in its content for swimming learners the teaching of values and concepts associated with health and disease, and make public health a fundamental goal by promoting swimmer health, family health and changing behaviors and habits to care for health.(7:114).

Presentation and interpretation results of the third question:

What are the implementation methods of health educational guidebook for swimming school learners?

\section{Table (3)}

Estimated degree and percentage of sample responses of implementation methods of guidebook $(N=60)$.

\begin{tabular}{|c|l|c|c|c|c|c|}
\hline no & \multicolumn{1}{|l|}{$\begin{array}{c}\text { Implementation } \\
\text { methods }\end{array}$} & Agree & To some(extend & $\begin{array}{c}\text { Don't } \\
\text { agree }\end{array}$ & $\begin{array}{c}\text { Estimated } \\
\text { degree }\end{array}$ & Percentage \\
\hline 1 & Commanding style & 54 & 5 & 1 & 286 & $95.33 \%$ \\
\hline 2 & training style & 48 & 7 & 5 & 266 & $88.66 \%$ \\
\hline 3 & Exchanging style & 49 & 6 & 5 & 268 & $89.33 \%$ \\
\hline 4 & $\begin{array}{l}\text { Guided discovery } \\
\text { method }\end{array}$ & 57 & 3 & ---- & 294 & $98 \%$ \\
\hline 5 & Input and incorporation & 47 & 6 & 7 & 260 & $86.66 \%$ \\
\hline
\end{tabular}

From table (3) it appears that the percentage of sample responses of the research in contents form ranged from (83.33\%).

Style (4) has the highest response while style (5) has the lowest response.

A guided method of discovery is one in which the learners engenders is, or works, the discovery process and the essence of this method is the special relationship that developed between a swimmer and learner, in which the questions that the teacher asked about, lead to the conclusions that the learner makes that fit the questions. The swimming teacher makes all 
decisions about the pre-study stage and this method includes the motivation mediator relationship and response. (13:99).

Aladdin Eliwah points out that one of the main reasons for developing health experiences is to change people's perceptions about health and disease, and try to make health a target by helping the community's public health program and by trying to collaborate in their programs $(2: 26)$.

Besides, the health education is not limited to specific aspect of health, but it includes all the elements necessary for a health swimming school learner, where Ayman Soliman points out that these elements are inherently intertwined, and they affect each other (personal hygiene, healthy nutrition prevention of accidents, first aids and environmental health).(4:56)

\section{Presentation of the fourth question result:}

What are the evaluation methods the health education guidebook for swimming school learners?

\section{Table (4)}

Estimated degree and percentage for sample responses at evaluation method at $(\mathrm{N}=60)$

\begin{tabular}{||c|c|c|c|c|c|c|}
\hline No & Suggested basis & Agree & $\begin{array}{c}\text { To same } \\
\text { Extend }\end{array}$ & Don't agree & Estimated & Percentage \\
\hline 1 & $\begin{array}{c}\text { Cognitive } \\
\text { acquisition }\end{array}$ & 46 & 9 & 5 & 262 & $87.33 \%$ \\
\hline 2 & Value criterion & 45 & 7 & 8 & 254 & $84.66 \%$ \\
\hline 3 & Tracer card & 49 & 7 & 4 & 270 & $90 \%$ \\
\hline 4 & Critical facts & 51 & 4 & 5 & 272 & $90.66 \%$ \\
\hline
\end{tabular}

From table (4) it appears that the percentages of sample responses of evaluation method form ranged from (84.66\%--- 90.66\%) and the fourth method (critical facts) has the highest response while the second method (value criterion)has the lowest response.

The teacher's guide is a main tool of the teaching, learning and educational resource process that provides teachers and learners with knowledge and skills, the concepts, values and basic information needed to make the 
learning needed happen, it's the basic of the educational process which provides a general frame work for the subject and instructs the learner and what will be acquired of information and skills (10-79)

The concept of evaluation can be applied in all educational situations whether its individual or programs or evidence evaluation in order to determine the effectiveness of the activities to be evaluated according to clear specific tests and make sure that part has fulfilled the goals of the learning process, also to learn about variables that affect the execution of given activity or program on characteristic group. (11-25)

Hazem Mohammad Youssef (9)(2008) study indicates that programmer evaluation process should be achieved at least annually, to ensure that the program achieved its goals and achieved its desired results, and evaluation process has many advantages, as it helps to achieve the usefulness of services provided to target group, it also helps to develop service delivery methods in order to save time and money .

From the foregoing, the evaluation includes a series of ongoing and sequential processes through which the objectives of the educational or training curricula can be defined, knowing the limitations and weaknesses to address them, and knowing that the goals of the evaluation are not only to determine the progress made by the apprentice or learner, but also to adjust the experiences which offered by the swimming teacher to the learners or to adjust the way of experience.

Also the accuracy and integrity of the evaluation process depends on the information and how to obtain it using measuring, testing and other methods that provides us with quantitative or non- quantitative data.

\section{Conclusions:}

1. Preparation of a health education guide for swimming school learners.

2. The proposed manual contains objectives along with implementation method and evaluation of the proposed manual.

3. The most important objective of the proposed guidebook that 


\section{researcher found was to:}

- Recognition of health concepts associated with healthy education of swimming learners.

- Recognition of health services linked to healthy swimming education.

- Recognition of health care related to healthy swimming education.

- Promoting health awareness among swimming learners.

- To develop and support healthy swimming trends.

- Learning about proper swimming habits.

- The rules for swimming in perfect conditions.

- The content of the guide was threefold which are the true health culture of swimming learners, the healthcare for swimming learners, and health services for swimming learners.

\section{the top three axis contents were:}

- Following the public and personal hygiene of swimming learners

- Emergency, first aid and treatment for swimming learners,

- Teaching learners the healthy rules for swimming.

- Healthy environment of swimming pools.

5) The researcher came up with a number of methods of implementing the suggested guidebook, and they are:

- Commanding style

- Training style

- Exchanging style

- Guided discovery method

- Input and incorporation style

- 6-The researcher found that the most important method of evaluation used for the guide was:

- Cognitive acquisition

- Value criterion

- Tracer card

- Critical facts 


\section{Recommendation:}

1-The need to publish this guide book for swimming teachers at various swimming schools.

2-conduct further studies to build and design proposed health education guides for different individual and group sports.

3-Attention to health education and cultural awareness of health important.

\section{References}

1. Ahmed mohammed Badah:Health culture,Al-Masira house,Jordan, 2013.

2. Aladin Eliwah:sports health,Monshat Al-Maaref,Alexandria,2006.

3. Awad Mohammad Al-Abd:A healthy culture for everyone, AlRoshed library,Al-Reyadh,KSA,2002.

4. Ayman solaiman Mozahra:Health education,Ministry of culture Publishing house,Amman,Jordan,2014.

5. Bahaa_Eldin salama:Health aspects of sports education,The Arabic thought house,cairo,2011.

6. Baltimore County :Public School Personal Learning Styles, Office of Instruction Technology, 2007.

7. Cowley, james: Health Education for swimmers in Public schools, Harper and Row, London, 2009

8. Dorid Majid Hamid El-Hamadani:Recent scientific foundation and concepts in swimming education and training,Saladin publishing house,Arbil,Iraq,2012.

9. Hazem Mohammed Youssef:corrective study for out door recreation Programmes,Masters letter,faculty of physical,AlMansoura,university,2008.

10.layla Al-sayed farahat:Measuring and testing in physical education,fourth publish,cairo,book center for publishing,2007,page19.

\section{Marawan Abd-El Majid and Mohammed Jasim Al-} yasira:Measurement and evaluation in physical and athletic education ,first publish,Al-waraq institution for publishing and distribution,Amman,2003. 
12. Miller, Edward \& Almon, Joan.: Crisis in the Kindergarten Why Children Need to Play in School, Alliance for Childhood, 2009

13.Mohammed Al-Hilal:Education design is theoretical and practiced,Al-Masira house for publishing,Amman,2016.

14.Mona Mohammed Ali:Early childhood ecology and its applications,Al-Masira house,Amman,Jordan,2016.

15.Nisreen Nadi Abd el-jid Mohammed:Guide book for health education of primary school sports teachers ,phd,faculty of physical education,Assuit university,2011.

16.Samia Mansour Nasser:The level of health education of female applied science students at the university of "om-alQura"and its relation to their health trends,published Masters letter,Al-Manzoma House,KSA,2016.

17.Waad farahat:physical education curriculum assessment, Raslan in stitution for publishing ,Damascus, 2008.

18.World Health Organization:. World health statistics. WHO Library Cataloguing-in-Publication Data, 2018 


\section{Annex guidebook to proposed health}

\section{$\underline{\text { Education for swimming school learners }}$}

\section{Presentation of the guidebook:}

\section{Whose guidebook is this?}

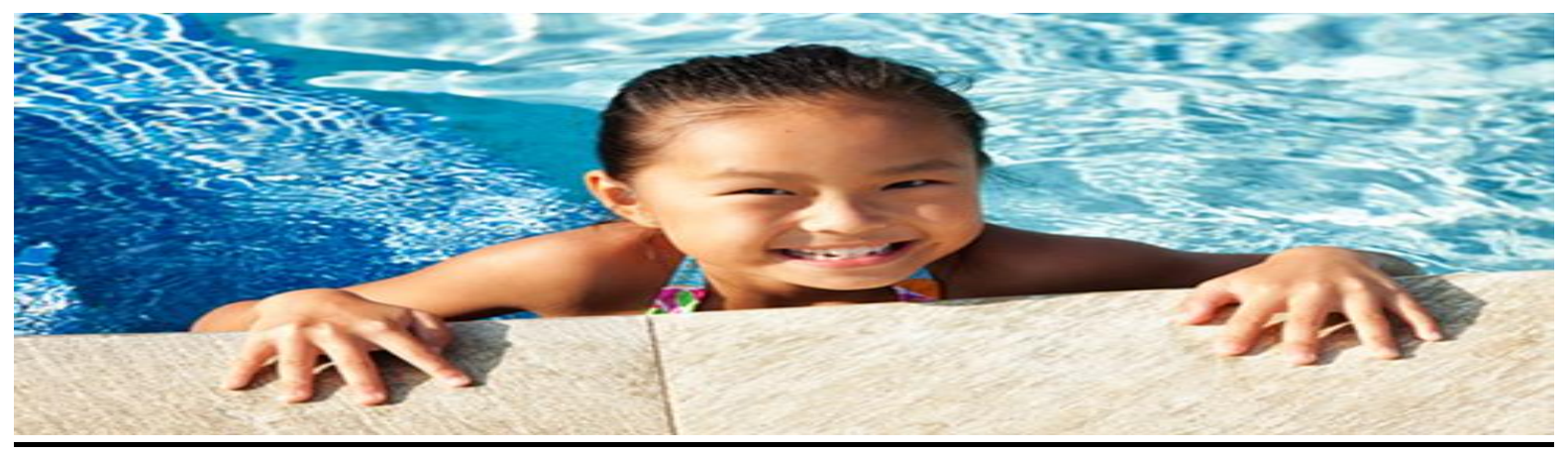

We present this guide to the tutor, swimmer and caretaker of his children while he is swimming, all three are essential for successful learning and hygiene at swimming schools .so the researcher is interested in preparing this manual, which provides guidance and suggestions to help her teach swimming and preserve the health of the swimmer by acquiring healthy habits to become a daily habit of swimming learners.

\section{How was it prepared?}

It has explained what is to be offered to swimming learners in various swimming schools.

\section{How do you use this?}

Given the growing awareness of the importance of swimming for all ages and its positive effect on all aspects of the health of its practitioners, it was necessary to prepare a health education manual for swimming learners who could consult at any time and learn how to practice before and after using the pool, and 
through that it can be prevent many illness and health problems that can avoid with this guide.

The researchers wishes all the swimming teachers well and swimming learners good health and pleasure.

\section{Good luck}

\section{The researcher}

\section{Public health objectives of the manual:}

1- recognition of health concepts associated with healthy education of swimming learners.

2-promoting health awareness among swimming learners.

3-learning about proper swimming habits.

4-the rules for swimming in perfect conditions.

\section{The importance of guidebook:}

To sharpen the swimming practitioners and provide them with health information and knowledge.

\section{Prevention is better than cure:}

There is no real prevention of the various kinds of diseases that we have mentioned, but there are measures that could reduce the incidence of these diseases.

1. The first step is to find the best places to swim.

2. At the level of commercial swimming pools, it is necessary to select those with a high reputation for hygiene and to follow the instructions of health authorities, this makes it possible to look at its records, know its health his story and ask friends and relatives. 
At any case, one of the most importance ways to avoid fall ill is to avoid swallowing water while swimming.

\section{Health culture:}

1_means the presentation of health information, data and facts that relate to health and disease, it includes:

\section{a) providing health information and knowledge:}

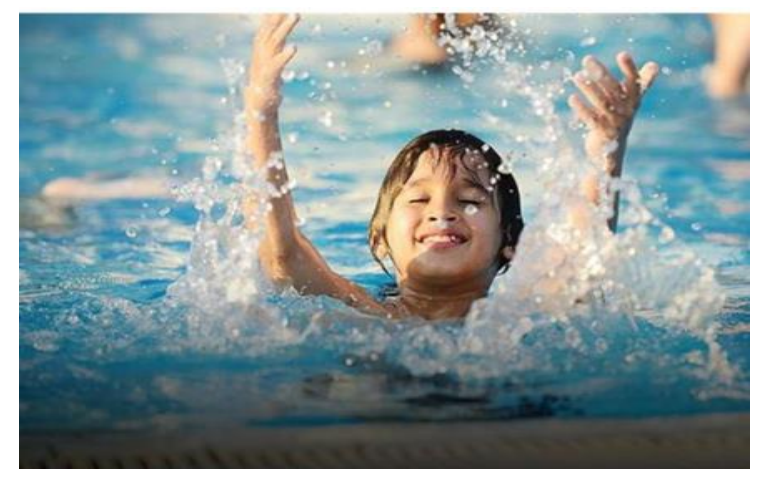

- Health: state of physical, psychological and social well-being and not merely being free from disease or infirmity.

- Health awareness: learning to swim with information, facts and a sense of responsibility for their own health and that of others.

- Health education: The process of translating known health facts into healthy individual and community behaviors using modern pedagogical methods.

\section{b) Public and personal hygiene:}

- It is a set of habits that a person is bound to observe in order to maintain his energy, vitality, health, personal appearance and respect for others.

\section{Importance of personal hygiene:}

- Rid the body of the stench (bad smells).

- Keeps the body healthy from many diseases like skin diseases.

- Protects from having many psychological problems such as stress and depression, increase Self-esteem.

\section{Diseases caused by poor hygiene:}

c) Diarrhea and dysentery. 
d) Incidence of intestinal worms of various kinds.

e) Various skin diseases.

f) Inflammation of the ear.

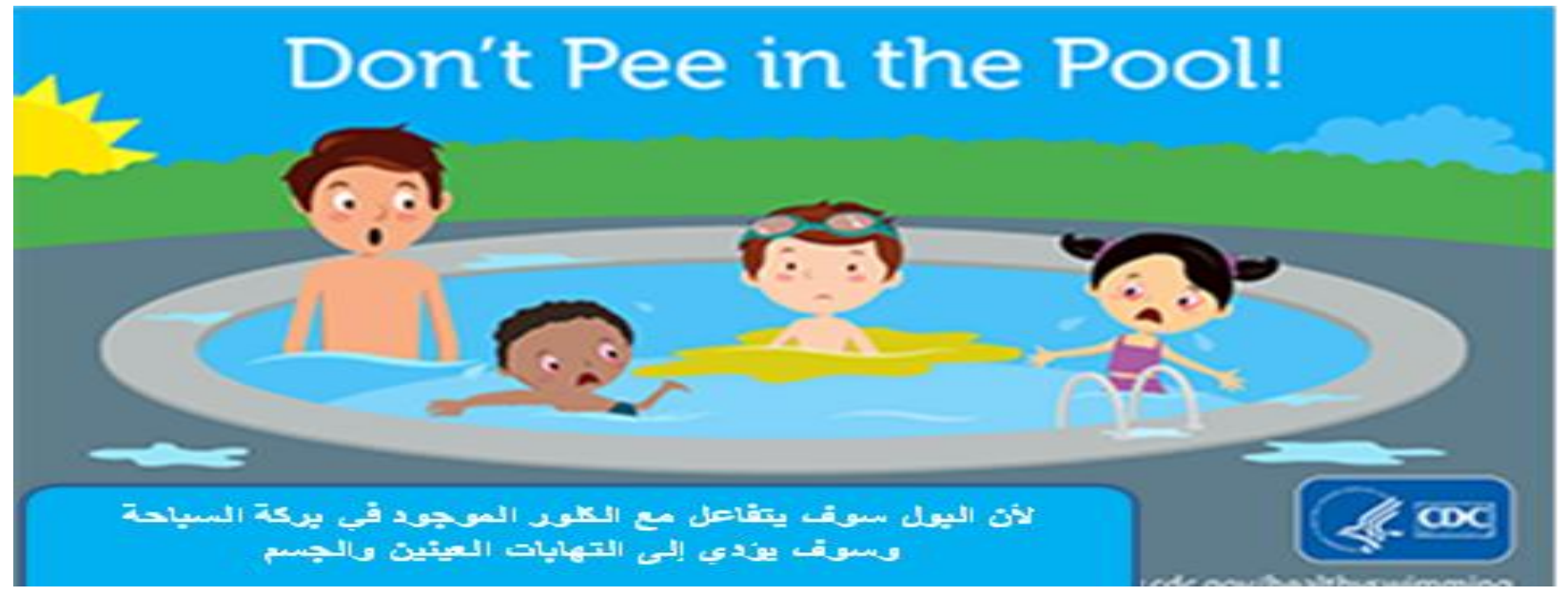

\section{Sanitary requirements for swimming pools:}

1. You shouldn't play bikes or any others toys you can ride by the pool.

2. Under no circumstances should an electrical device be placed near the pool.

3. You shouldn't run around the edges of the pool.

4. The pool should be surrounded by a barrier that prevents children from sneaking in every way and it shouldn't be climbable at least $120 \mathrm{~cm}$ high.

\section{How did the infection happen in the swimming pools?}

Because of direct contact between the people involved in the pool, also because the number of people using these pools.

It accumulates fats that the body excretes, in addition to cosmetics residue or the use of towels or shared shoes or the contamination of floors around swimming pools by inflected people or swallows water contaminated with human excrement or urine as result of urination in the swimming pools. 
Also the sterilizer consist of chlorine, is itself a pathogen that can cause many skin diseases, especially with direct sunlight and a lack of chlorine to eliminate all types of bacteria.

\section{The sources of infection are plentiful and the most important are:}

1. Polluted objects: like comb, brush, slipper ... etc.

2. Direct infection: occurs especially among practitioners if a swimmer has skin disease or diarrhea.

\section{Important and general instructions}

\section{Important and general instructions:}

Body cleaning:

\section{Skin, nails and hair cleaning:}

-The skin is of the highest importance to the

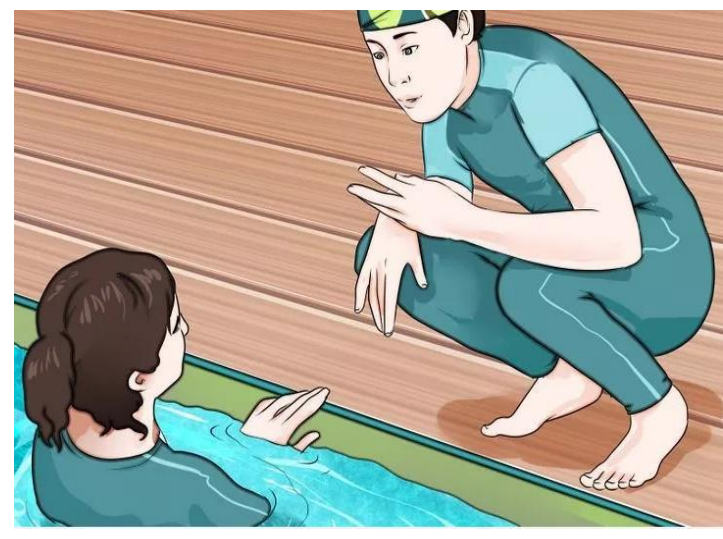
human body.it is constantly exposed to the dust and bacteria in the air and the secretion deposits that occur after sweat evaporates.

-Everyone of us has to keep his body clean by washing it with soap and water, washing away the dirt and the stench, and exposed organs need to be washed more than once a day.

\section{Face and neck cleaning:}

Face and neck must be washed every morning and night with soap and water, and every time the child expose to dust or sweat.

\section{Hand cleaning:}

The hand is an important organ of the body, but it plays an active role in the transmission of disease since it is used extensively in a variety of tasks required by daily human. 
Needs and therefore must be washed with soap and water.

\section{Nails cleaning:}

Nails are considered the cleaning body mirror, so they have to be cleaned every day to get of the dirt in them.

\section{Feet cleaning:}

The feet are contaminated, so they need to be washed with soap and water several times a day, especially before bed, and they need to be properly dried to avoid possible disease.

\section{Hair cleaning:}

Daily hair comb is considered to be a factor in hair conservation because it enables the removal of dust, crust and parasites, preferably as a personal comb, to avoid the transmission of microbes and parasites.

\section{Swimming pool using instructions:}

\section{First: before using the pool:}

1) Taking bath before entering the pool.

2) For young children, it's better to go to the bathroom to pee to ensure they don't pee in the pool.

3) Babies should wear baby diapers.

4) Using personal tools is important and necessary, it includes :

*towels.

*Hair headgear.

*wearing slippers in the shower.

5) Drying the feet before the pool.

6) Nails cutting before swimming. 


\section{Second: while swimming:}

1. Wear earplugs and headgear.

2. The eye can be protected by wearing swimming glasses which help prevent water contaminating chlorine from reaching the eye, which could cause irritation to the conjuncture.

3. No diving, no jumping in the shallow pool.

4. Following the swimming instructor's instructions, because his primary duty is to preserve the learners.

5. Make sure you don't swallow pool water at all.

6. Not to swim with diarrhea so you don't infect other.

7. Take a break during practice to avoid exhaustion.

\section{Protection from sunlight and swimming burns:}

Most parents know the importance of using sunscreen and try to avoid their kids getting sunburned; unfortunately, they may not be fully successful and there may burns. Here we remind you of some of mistakes that many of you make such as:

- Not to use sunscreen, especially in spring time, early summer, where sunlight is not so strong.

- Leaving some parts of the body like nose and shoulders, as all parts are subject to burn.

- Not to use sunscreen in time; it should be put before sun exposure by 30 minutes.

- To avoid sunburns, children would rather be given head covering and sunglasses to wear in the sun.

\section{Dehydration and dermatitis:}

One of the most common problems of the summer swimmers is skin dehydration and severe inflammation .it's caused by long periods of exposure to the sun's 
harmful ultraviolet radiation where sunrays works on dry, coarse skin, inflammation and intense redness .so sunscreen should be applied to the skin before swimming because it protects the skin from harmful sunlight symptoms and infections.

\section{Skin disease:}

\section{External ear infection (swimming ear):}

This infection affects all ages and occurs within days of swimming, including itching, redness, ear infection, squeezing and pus production.

It usually appears when there's water for a long time inside the ear canal to create a suitable environment for germ growth, which happens in swimming pools where it can't pass from person to another.

This bacterial infection also occurs in the external ear canal, often several days after exposure to a swimming pool injury.

When water stays in the ear canal for a long time. The hierarchical environment that helps the growth of bacteria, and the unbalanced levels and ph degree play an important in the disease.

\section{Protection:}

Protection by wearing swimming headgear or earplugs to prevent water from reaching the ear, which needs to be properly dried in towels after swimming. The hair dryer can be used to remove excess ear water, and anything in the ear, such as pencils, fingers or cotton sticks, should be avoided, so as to protect the ear wax from infection. We can also use special medical drops. 


\section{What better way to prevent swimmer's ear disease?}

Swimmer's infection is often healing by prescription earplugs, to protect the swimmer's ear:

Keep the ear dry from fluids: A child should wear earplugs while swimming and after that dry the child's ear by gently scanning the external ear using soft towel or hairdryer .Get the hair dryer to the minimum position and carry it at least 30 centimeters from the ear.

\section{The foot cougar (athlete's foot):}

Contact of the foot with the pool attachments increase the increase the chance of developing skin mycopal foot disease, causing severe pain,

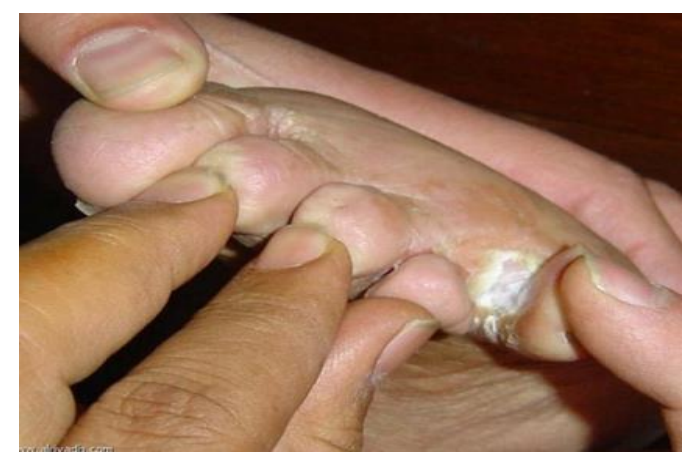
itching and burning, and the skin in the affected area can flake and bleed.

The skin infection on foot occurs by certain types of fungus and appears between the first and second toes, but it can affect any part of the foot and spread by contact with infected skin in specific places like swimming pools, and the treatment often requires to put lotion on the skin and sometimes oral therapy.

\section{Protection:}

- Nails cutting and cleaning.

- Keep your foot clean, dry them, and avoid wearing closed shoes and unmade cotton socks.

- To avoid this disease, doctors are advised to wear shoes when visiting swimming pools and to avoid wearing others shoes. 


\section{Osteoporosis:}

The edema is small appendages usually shown in heels or other weight -bearing areas. It is caused by the human papillomavirus. The virus enters the body through small lacerations or fractures or other frail underfoot areas.

\section{Protection:}

- Avoid direct contact with edema, including that in your body; wash your hands after touching it.

- Avoid walking barefoot around swimming pools and changing rooms.

- Avoid catch or scratch it.

\section{Skin infections:}

It's caused by pseudo-bacteria. Rash occurs day's after direct skin contact with contaminated water. Symptoms include itch, which can lead to redness and swelling of the skin, and pus in hair follicles.

Bathrobes should not be left for a long time to

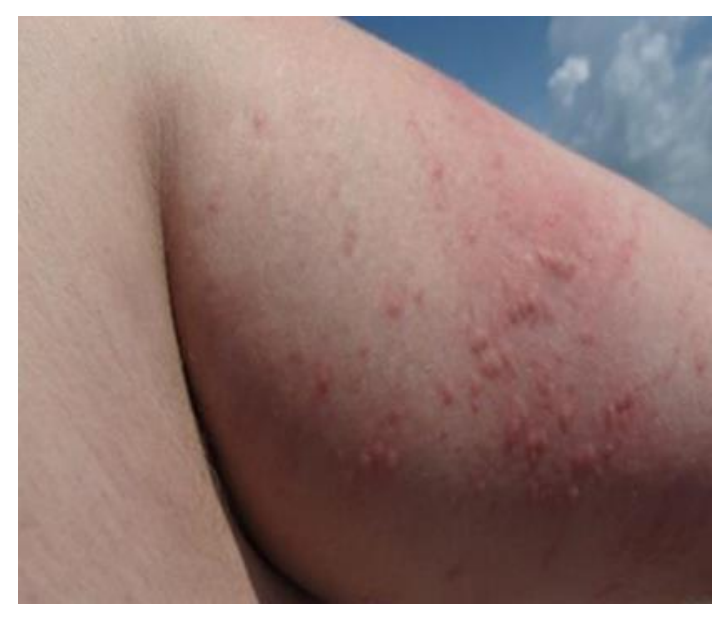
dry on a daily basis; Disinfectant and acidity help prevent dermatitis.

\section{Sycophant:}

It is a viral dermal infection transmitted by water, and although the virus itself is not considered dangerous, one can carry it for two years and develop skin scars.

Treatment: it's usually chemical, ironing or cooling.

\section{Swimming pools outburst:}

Sometimes people develop skin irritation after swimming in swimming pools because of prolonged exposure to chlorine in the water, although chlorine is 
important for killing bacteria and keeping the water sterilized but the length of time in the pool means a long period of exposure to chemicals, resulting in allergies to chemicals or skin irritation.

\section{Protection and treatment:}

- The best treatment for these conditions to give the body enough comfort to recover from these symptoms.

- Do some proper lotion before we go down to the pool.

\section{sinus pool:}

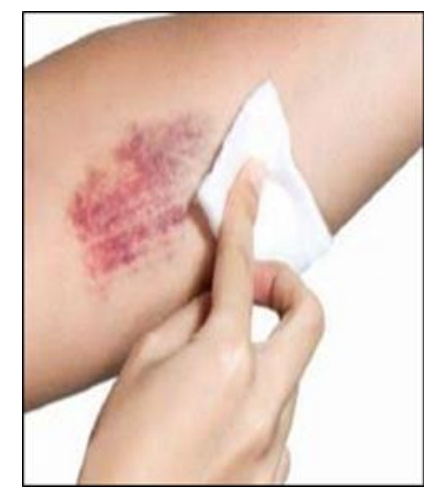

It's a chlorine skin condition caused by bacteria called (mycobacterium marinum) where this bacteria is transmitted by any incision in the skin and then through the body.

The injured areas are usually elbows, knees or hands, and after three weeks the injury develops into a wound on the surface of a red outcrop that later turns purple.

\section{Treatment:}

The antibiotic (minocycline) is usually recommended so the inflammation can be overcome.

\section{First aids for injures the swimming learners may have:}

1. Bruises: it's the destruction and rupture of the superficial or deep tissue of the tissue cells, whether soft, like skin, or hard like bones ,joints and muscles.

As result of tissue destruction, capillaries rupture, internal subcutaneous spillage and discoloration of the skin. 


\section{Causes:}

1. Collision with soft solid object during performance.

2. External shocks are like sudden hits on a solid object.

\section{1-skin bruises:}

\section{Types:}

a) Simple skin bruise: it's the one that may not feel the moment it happens but when finishing the game.

b) Hard skin bruise: where an individual cannot continue to play and it's symptoms appear at the time of injury.

\section{Symptoms of bruises:}

1. Feeling in pain.

2. Skin discoloration and tumor.

3. Elevated temperature of affected part.

4. Not being able to move the infected part.

\section{Hard skins bruise aid:}

1. Cold water compressors, two - three times in two days.

2. Bind the injured part with a ligature that compresses the tumor.

3. Raise the injured organ if possible with rest.

\section{2) Muscle bruises:}

The most exposed muscles in the body are femur muscles, the calf of the leg, and combination of the shoulder muscles and the hand.

\section{Causes:}

Falling or scratching outside the pool while running or in the pool through friction with bathroom wall. 


\section{Symptoms:}

1. Feeling in pain.

2. Not being able to move the injured muscles.

3. Within 24hours, a tumor and redness developed due to internal hemorrhage from a ruptured capillary.

4. Elevated temperature at the part of the contusion.

5. Skin changes color from red to blue, then gradually changes to green then yellow then normal in a week.

\section{Aids :}

1. Best rest to relieve muscle tension while the swimming teacher calms psychological the learner.

2. The swimming teacher asks the injured learner how and why the injury occurred and where he feels the pain.

3. Local anesthetic is used the site of the injury, like ethyl chloride.

\section{4) Bones bruises:}

The most exposed areas of the body are skin covered bones, such as exposed areas of the facial bones, the anterior part of the tibia ,the tibia , the heel, the elbow and the knee.

\section{Causes:}

1. Direct collision with un sharp hard bodies.

2. Violet blows.

\section{Symptoms:}

1. Intense pain at the part of bruise, especially in exposed bones.

2. The discoloration of the skin where the injury occurred.

3. Not being able to move damaged bones. 


\section{Aids:}

1. Using local anesthetic like chlorythel.

2. Pressing the trauma site to stop the swelling.

3. Cold compresses.

4. See the specialist doctor.

\section{4) Joints bruises:}

The most affected joints of the body are the joint of the foot, knee, elbow, shoulder, cleaver, and tones.

\section{Causes:}

1. Direct collision with hard bodies.

2. Sudden falling over it.

3. Exposing to violent blows.

\section{Symptoms :}

1. A cute joint pain due to increased amniotic fluid.

2. Not being able to use the joint normally.

3. Elevated temperature at affected part.

Aids :

1. Application of a topical tranquilizer to and around the affected joint.

2. 20 to 40 minutes of crushed ice compressors to control the amount of bleeding, internal spills and tumor control.

3. Relief of one to two weeks, depending on the severity of the injury.

\section{5-contractions:}

Common injures among swimming learners, although repetition, are not serious injuries. 


\section{Definition:}

It's an involuntary muscle contraction that happens to a swimmer all a sudden, and it can happen one muscle or a set of muscles.

\section{Cause:}

1. Lack of oxygen in the muscle or unbalanced salts in the body.

2. Muscles exposure to sudden cold after muscle temperature spikes.

3. Un prepared and warm up enough before practice.

\section{Types:}

First type $:$ intermitted contractions with several involving muscle contractions, then muscle relaxation, then muscle contractions, then relaxation.

Second types: a continuous contraction in which muscles contractions occur without muscle relaxation.

\section{Contractions aids (treatment):}

1. The shrunken muscles reversed the muscle.

2. Muscle massage after muscle cramping, not right away, because it increase muscle cramping.

3. Warming the muscle by making a muscle hot bath.

\section{2-Cramping and muscle laceration :}

Tensile tension or tear may occur in the voluntary muscles, such as the upper or lower extremities, or involuntary muscles, such as the stomach and intestine.

\section{Muscle tension definition:}

Abrupt muscle spasms are cause by involuntary

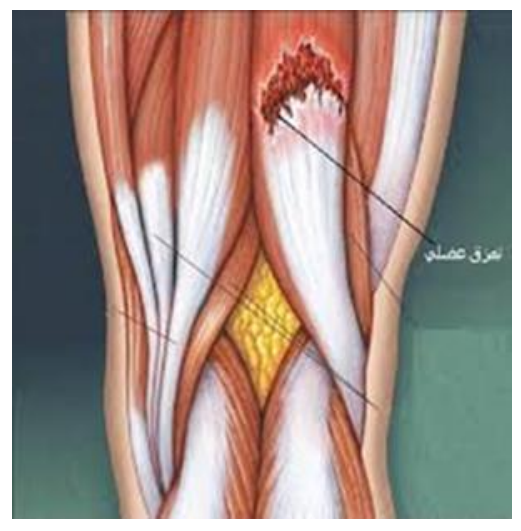


contractions that either occurs during the rest period, during physical exertion or during sleep.

\section{Muscles rupture definition:}

A sudden involuntary abruption of muscle height result in a slight or severe rupture or a total rupture or total, either in the muscle - wrapping bag, inude the muscle or in the tendons.

\section{Causes of muscle laceration:}

1. Sudden abrupt muscle contractions without the muscles being prepared to do this.

2. Neglect enough is warming - up.

\section{Symptoms of muscle laceration:}

1. Feeling pain at injury site which depends on the degree of the injury and where it occurred.

2. The injured muscles are unable to function or move.

3. In case of renal rupture, it is noticeable that there is lower part at the area of injury and there is a muscle - shaped deformity and that the two of them are disengaged.

\section{Laceration aid:}

1. Full rest of the learner physically and psychologically to avoid shock.

2. Put the injured muscle in completely relaxing position to reduce stress or reduce stress due to muscle rupture.

3. Use of cooling devices such as cold water compresses or snow compresses three times a day for $24-48$ hours depending on the severing of the injury. 


\section{$\underline{\text { Twist (sprain): }}$}

Definition: joints distance is abnormal as result of incorrect use of the joint or twisting in a direction where movement is longer possible for these joints surfaces to return to normal immediately after the accident.

\section{Causes:}

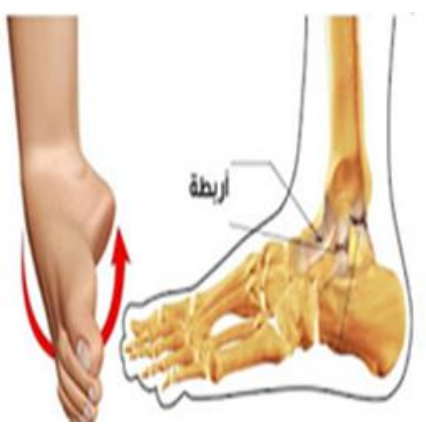

1. Sudden joint twist.

2. As a result of a violet movement in specific direction, due to an external force that is beyond its capacity to with stand.

3. Falling on one the joints.

\section{Symptoms:}

1. Severs pain due to ruptured ligaments and tissues around the joint

2. Elevated temperature at the joint.

3. Not being able for walking.

4. Skin discoloring into blue at the injured part.

\section{Aids:}

1. Cold water or ice compresses should be used because of internal bleeding in the affected joint to stop or reduce it for 20:30 minutes.

2. Immediately after injury and to maintain cold compresses for one or two days, depending on the severity of the injury.

3. Stabilizing injured joint in proper anatomical position using compressive ligature.

4. The entire rest of the body weight of the joint for $24: 48$ hours. 


\section{تعزيز سلامة الأطفال من أمراض المسابح}

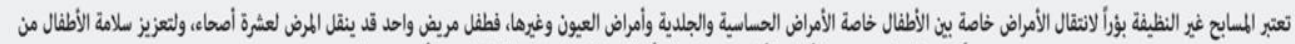
أمراض المسابح، بنصح الأطباء الأهل بعدم إرسال أطفالهم للمسابح في حالة إصابتهم بأي مرض عابران.

:
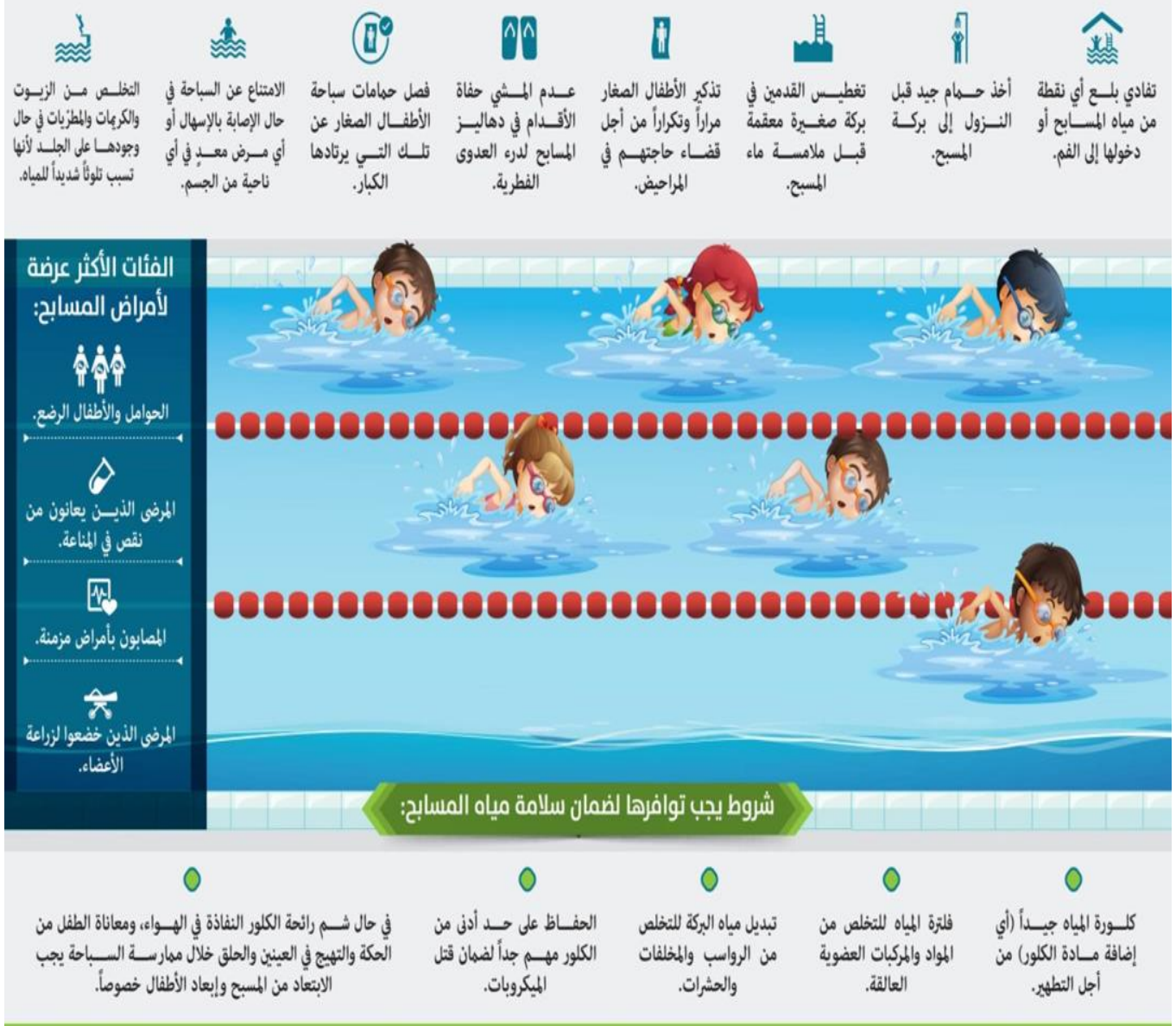